\title{
Screening of Antioxidant and Radical Scavenging Activities of Some Omani Medicinal Plants
}

\author{
Saleh Al-Busafi*, Mubarak Al-Riyami, Khadija Al-Ouwaisi and Abdulkhader Hisham
}

Department of Chemistry, College of Science, Sultan Qaboos University, P.O. Box 36, Postal code 123, Muscat, Sultanate of Oman, *Email: saleh1@squ.edu.om.

\section{الهثف عن أنثطة مضادت التُٔسد وكبح الثوارد لبهض النبلتات اللببة في عملن}

\section{صالح البوصلي،مبارك الربلي،خيجة العوبمي و عبدالفالر هشلم}

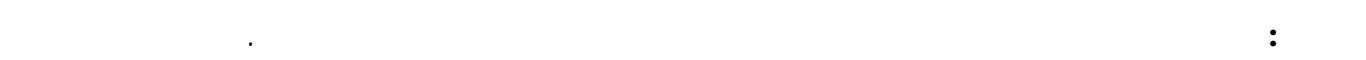

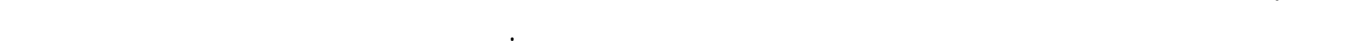
فروسيا هوسكنشي لها لنثطة مرتفعة لمضادات التلكسد وكنح اللثوارد.

\begin{abstract}
Butanol extracts of nine medicinal plants, Cressa cretica, Ziziphus spinachrist, Acacia tortilis, Tephrosia haussknechti, Aristolochiae bracteolata, Citrullus colocynthis, Teucrium mascatense, Rhazya stricta and Nerium oleander, found in Oman were screened for their antioxidant activity using phosphomolybdenum complex assays and their radical scavenging activity using DPPH assays. Ocimumi basilicum, a plant with well documented antioxidant activity, was used as a reference. $A$. tortilis, and $T$. haussknechti extracts possessed very high antioxidant activity (AOA) and high radical scavenging activity (RSA).
\end{abstract}

KEYWORDS: Antioxidant activities, radical scavenging, DPPH, phosphomolybdenum complex.

\section{Introduction}

pices have been used since ancient times to improve taste and aroma of different types of food and some of them are well known for their antioxidant properties (Madsen and Bertelsen, 1995). Antioxidants are widely used as additives in food, pharmaceutical, and cosmetic industries to provide protection against oxidative degradation. Numerous degenerative diseases such as brain dysfunction, cancer, heart diseases and immune system decline could be the result of cellular damage caused by reactive oxygen species and free radicals present in human diet and antioxidants may play an important role in the prevention such diseases (Aruoma, 1998).

A great number of aromatic, spicy, medicinal and non-medicinal plants contain chemical compounds exhibiting antioxidant properties. Several studies were carried out on plants, such as rosemary and sage have led to the development of natural antioxidant formulations for food, cosmetic, and other applications (Cuvelier et al., 1996). However, scientific studies on the antioxidant properties of several plants used in Omani traditional 


\section{SALEH AL-BUSAFI, ET AL.}

medicine are still rather scarce. Therefore, the evaluation of such properties seems to be a useful task with a view to find new sources of natural antioxidants.

The present work deals with preliminary studies on the antioxidant and radical scavenging activities of the n-butanol extracts prepared from the following plants: Cressa cretica (Convolvulaceae), Ziziphus spina-christi (Rhamnaceae), Acacia tortilis (Leguminosae), Tephrosia haussknechtii (Leguminosae), Aristolochiae bracteolata (Aristolochiacae), Citrullus colocynthis (Cucurbitaceae), Teucrium mascatense (Labiatae), Rhazya stricta (Apocynaceae) and Nerium oleander (Apocynaceae) which are readily available plants growing in northern Oman. To the best of our knowledge, only little information on the antioxidant and radical scavenging properties of these plants is available in the literature. C. cretica is an annual plant that grows in saline soils and is used to treat minor wounds. The aerial parts of C. cretica are source of flavonoids (Shahat et al., 2004), and terpenoids (Ramachandran and Ali, 2003). Antioxidant properties of the plant have not been reported. Z. spinachristi is one of the five popular trees in Oman. The fruits are edible. The crushed leaves are used as a natural cleaning as well as a conditioner for the hair. Hair washed with Ziziphus leaves becomes particularly lustrous and soft (Miller and Morris, 1988). It has been reported that the volatile fraction of flowers and leaves of $Z$. spina-christi possesses antimicrobial activity (El-Hamouly and Mohamed, 2001) and the plant is rich in flavoniod glycosides and triterpenoid saponins.

A. tortilis is the most commonly seen tree in Oman (Miller and Morris, 1988). The plentiful flowers of $A$. tortilis attract honey bees and these flowers are known to produce the best honey in Oman. Even though the reports on flavonoid isolation from A. tortilis (Muhaisen et al., 2002) are available in the literature, the information on antioxidant properties of this plant are not found.

T. haussknechti is a bright-flowered shrub of rocky, lower altitude hill-sides which is the most common Tephrosia species in northern Oman (Mandaville, 1978). The leaves of T. haussknechti are used to treat earache, swollen joints (Ghazanfar, 1994) but no antioxidant properties are reported .

A. bracteolata is a source of aristolochic acids (El Tahir, 1991), which is used to treat wounds, snakebites but no antioxidant properties are reported in the literature.

The seeds of C. colocynthis are used to treat tumors and the green flesh of the immature fruit is taken in small quantities as a purgative (Miller and Morris, 1988). The fruits of C. colocynthis contain flavones (Maatooq, et al., 1997), triterpenes glycosides (Hatam, 1989) but antioxidant properties of the plant have not been reported.

T. mascatense is an aromatic perennial, a native of Oman which is used in traditional medicine for fever, diabetes and stomach pain (Mandaville, 1978; Ghazanfar, 1994). The composition and antimicrobial activity of this plant was recently reported (Hisham et al, 2006) no studies on the antioxidant properties of this plant is available.

R. stricta, known as 'harmal' in Arabic is used in Arabian folk medicine as a remedy for respiratory ailments and fevers (Mandaville, 1978). Alkaloids have been isolated from the leaves of $R$. stricta (Atta-urRahman and Habib-ur-Rahman, 1996) and antioxidant action of the leaves extract has been reported (Ali et al., 2000)

In traditional medicine, various parts of $N$. oleander are used for treatment of cough, swellings, eyes and skin diseases. Methanolic extract of the fresh leaves of $N$. oleander showed central nervous system (CNS) depressant effect in mice (Begum et al., 1999). Flavonoids were present in all organs of the plant (Duret and Paris, 1977), but roots and the leaves of $N$. oleander contain triterpenoids (Begum et al., 1997) with no antioxidant properties reported in the literature.

It was noticed that the antioxidant activity of the above selected plants were either not investigated or poorly investigated and therefore testing of their antioxidant and antiradical properties is of interest, primarily to find new promising sources of natural antioxidants. 


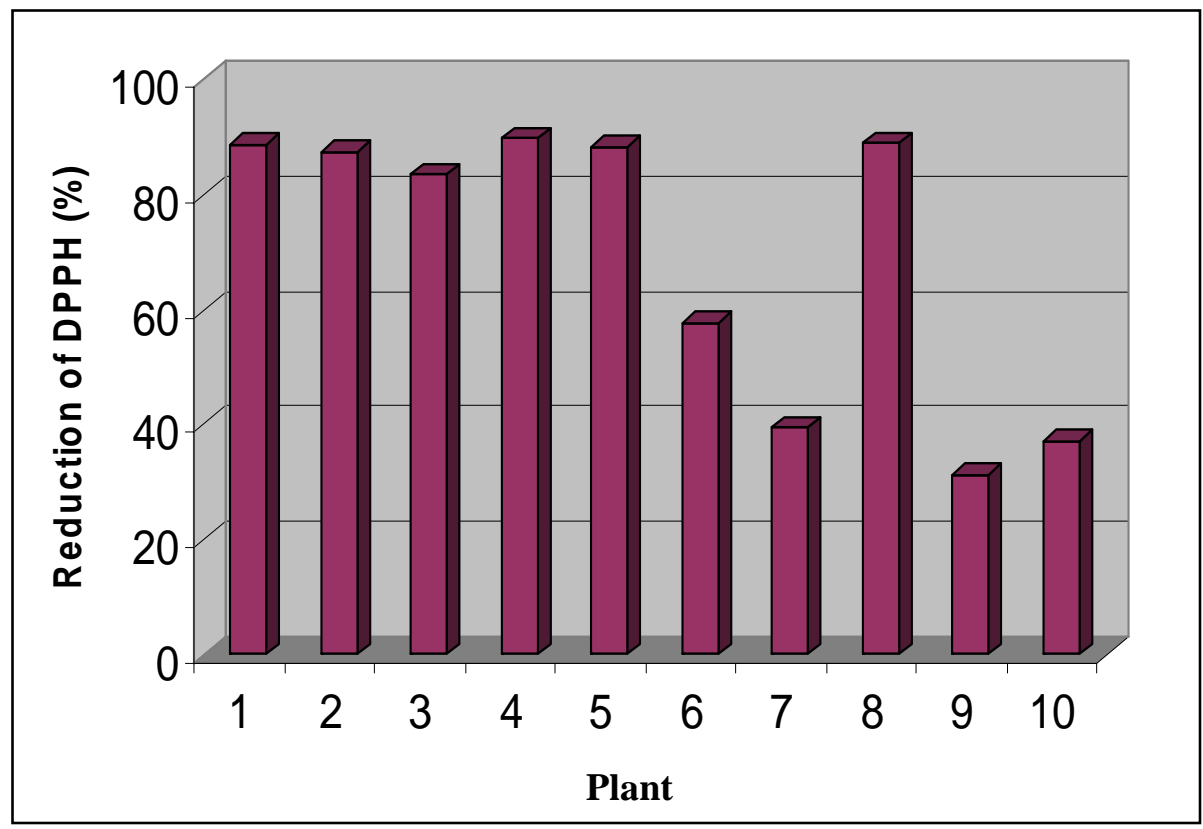

Figure-1: DPPH radical scavenging activities of $n-\mathrm{BuOH}$ extracts.

1. Oscimum basilicum; 2. Cressa cretica; 3. Ziziphus spina-christi; 4. Acasia tortilis; 5. Tephrosia hausknechti; 6 Aristolochia bracteolate; 7 Citrullus colocynthis; 8.Teucrium mascatense;

9 Rhazya stricta;10. Nerium Oleander

\section{Results and discussion}

\subsection{DPPH radical-scavenging activities}

The n-BuOH extracts of the plants were prepared as described in section 3 and their free radical scavenging activity was determined by DPPH free radical method (Brand-Williams et al., 1995). The n-BuOH extract of Ocimumi basilicum (Labiatae), a plant well known for its antioxidant and radical scavenging properties, was used as a reference.

The 1,1-Diphenyl-2-picrylhydrazyl (DPPH) radical is a stable radical with a maximum absorption at 517 $\mathrm{nm}$. When $\mathrm{DPPH}^{*}$ reacts with an antioxidant compound, which can donate hydrogen, it is reduced and the color changes from deep-violet to light-yellow. The results of DPPH radical-scavenging activity of $n$-butanol extracts are shown in Figure 1.

Six out of nine $n-\mathrm{BuOH}$ extracts used in the present study showed high level of DPPH scavenging activities ie., C.cretica-87.7\%, Z. spina-christi-83.5\%, A. tortilis-89.8 \%, T. hausknechti-88.4\% and T. mascatense- $89.1 \%$. In fact the extracts of $A$. tortilis and $T$. mascatense are having remarkably higher level of radical scavenging activity compared to $O$. Basilicum. On the other hand, the extracts of A. bracteolate- $57.8 \%$, C. colocynthis-39.6\%, R. stricta-31.3\%, and $N$. oleander-37.2\% showed only moderate or weaker activities.

\subsection{Antioxidant activity evaluation by the phosphomolybdenum method}

The antioxidant activity of the extracts was evaluated by phosphomolybdenum method, which is based on the reduction of $\mathrm{Mo}(\mathrm{VI})$ to $\mathrm{Mo}(\mathrm{V})$ by the antioxidant compound(s) and the formation of a green 


\section{SALEH AL-BUSAFI, ET AL.}

phosphate/Mo(V) complex with a maximal absorption at $695 \mathrm{~nm}$. The results of antioxidant activity exhibited by different plant extracts are summarized in Table 1.

Table 1. Antioxidant activities of $n$-BuOH extracts

\begin{tabular}{|l|c|}
\hline \multicolumn{1}{|c|}{ Plant } & $A_{\mathrm{w}}{ }^{\mathrm{a}}$ \\
\hline Oscimum basilicum & 1.0 \\
\hline Cressa cretica & 0.78 \\
\hline Ziziphus spina-christi & 1.0 \\
\hline Acasia tortilis & 1.4 \\
\hline Tephrosia hausknechti & 1.0 \\
\hline Aristolochia bracteolata & 0.88 \\
\hline Citrullus colocynthis & 0.82 \\
\hline Teucrium mascatense & 0.97 \\
\hline Rhazya stricta & 0.75 \\
\hline Nerium oleander & 0.99 \\
\hline
\end{tabular}

${ }^{\mathrm{a}} A_{\mathrm{w}}$, activity relative to Oscimum basilicum on a weight basis

The extract of $A$. tortilis exhibited higher antioxidant activity than $O$. basilicum, while extracts of $Z$. spinachristi, T. hausknechti and $N$. oleander showed antioxidant activities, similar to the reference extract. The extracts of A. bracteolate, T. mascatense and C. colocynthis showed moderate antioxidant activities, whereas $C$. cretica and $R$. stricta exhibited only weak activities compared to the reference plant extract.

\section{Experimental}

\subsection{Reagents}

1,1-Diphenyl-2-picrylhydrazyl (DPPH), sodium phosphate and ammonium molybdate were purchased from Sigma-Aldrich and all solvents were of analytical grade.

\subsection{Plant material}

Ocimum basilicum (leaves and stems), Cressa cretica (leaves and stems), Ziziphus spina-christ (leaves), Acacia tortilis (leaves), Tephrosia haussknechti (leaves and stems), Aristolochiae bracteolata (leaves and stems), Citrullus colocynthis (fruits), Teucrium mascatense (leaves and stems), Rhazya stricta (leaves and stems) and Nerium oleander (leaves) were collected from Northern Oman during 2003 and were authenticated by Department of Biology, Sultan Qaboos University. The freshly cut plants were dried in the drying room with ventilation at ambient temperature prior to use for investigation.

\subsection{Extraction}

The dried, powdered plant materials were extracted with methanol $(500 \mathrm{~mL})$ at room temperature and the methanol extracts were concentrated under reduced pressure to get greenish viscous materials which were first partitioned with hexane $/ \mathrm{H}_{2} \mathrm{O}$, then with EtOAc/ $\mathrm{H}_{2} \mathrm{O}$ and finally with $n$-Butanol/ $\mathrm{H}_{2} \mathrm{O}$ to give hexane extracts, 


\section{SCREENING OF ANTIOXIDANT AND RADICAL SCAVENGING ACTIVITIES}

ethyl acetate extracts and $n$-Butanol extracts. The concentrated $n$-Butanol extracts were used for the evaluation of the antioxidant activities.

\subsection{DPPH radical-scavenging activity}

The free radical scavenging activity of the plant extracts was determined by DPPH free radical method (Brand-Williams et al., 1995). A $2.0 \mathrm{ml}$ methanolic solution of DPPH $(0.1 \mathrm{mM})$ was mixed with $0.1 \mathrm{ml}$ of extract solution $(0.1 \mathrm{mg} / \mathrm{ml})$ in methanol and, after $60 \mathrm{~min}$ standing; the absorbance of the mixture was measured at $517 \mathrm{~nm}$ against methanol as the blank on a UV/visible light spectrophotometer (Shimadzu UV 1650 PC, Japan). Triplicate measurements were made and the radical scavenging activity was calculated by the percentage of DPPH that was scavenged using the following formula:

$\%$ Reduction $=\left[\left(A_{\mathrm{B}}-A_{\mathrm{A}}\right) / A_{\mathrm{B}}\right] \times 100$

Where: $A_{\mathrm{B}}$-absorption of blank sample; $A_{\mathrm{A}}$ - absorption of tested extract solution.

\subsection{Evaluation of antioxidant activity}

The antioxidant activity of plant extracts was evaluated by the phosphomolybdenum method according to the procedure of Prieto et al., (1999). An aliquot of $0.3 \mathrm{ml}$ of sample solution (1 mM in methanol) was combined in a 4-ml vial with $3 \mathrm{ml}$ of reagent solution ( $0.6 \mathrm{M}$ sulfuric acid, $28 \mathrm{mM}$ sodium phosphate and $4 \mathrm{mM}$ ammonium molybdate). The vials were capped and incubated in a water bath at $95{ }^{\circ} \mathrm{C}$ for $90 \mathrm{~min}$. After the samples had cooled to room temperature, the absorbance of the mixture was measured at $695 \mathrm{~nm}$ against a blank. The antioxidant activity was expressed relative to that of Ocimumi basilicum (Labiatae).

\section{Conclusions}

The $n$ - $\mathrm{BuOH}$ extracts A.tortilis, T. mascatense and T. hausknechti were found to be the strongest radical scavengers in DPPH radical assay and the strongest antioxidants in phosphomolybdenum assay among the plants screened. They are promising plants for further investigation of antioxidant properties particularly A. tortilis of which antiradical and antioxidant activities were higher than that of $O$. basilicum.

In a previous work, we showed that aristolochic acid and aristolochic acid-D isolated from A. bracteolata, is as effective as vitamin C in antioxidant activity on a molar basis (Al-Busafi et al., 2004). The results in Table-1 suggests that the plants A. tortilis, T. hausknechtii and Z. spina-christi may have better antioxidants than vitamin C.

\section{Acknowledgements}

We acknowledge, with thanks, financial support from the Sultan Qaboos University. (Grant IG/SCI/CHEM/03/01).

\section{References}

AL-BUSAFI, S.; AL-HARTHI, M.; AL-SABAHI, B., 2004. Isolation of aristolochic acids from Aristolochia bracteolate and studies of their antioxidant activities. J. Science, 9: 19-23.

ALI, B.H., AL-QARAWI, A.A., BASHIR, A.K., TANIRA, M.O., 2000. Antioxidant action of extract of the traditional medicinal plant Rhazya stricta Decne. in rats. Phytotherapy Res., 14(6): 469-471.

ARUOMA, O.I., 1998. Free radicals, oxidative stress, and antioxidants in human health and disease. J. Am. Oil Chem. Soc., 75(2): 199-212.

ATTA-UR-RAHMAN, HABIB-UR-RAHMAN, 1996. Alkaloids of the leaves of Rhazya stricta. Fitoterpia, 67(2): 145-148.

BEGUM, S., SIDDIQUI, B.S., SULTANA, R., ATIYA ZIA, SURIA, A., 1999. Bio-active cardenolides from the leaves of Nerium oleander. Phytochemistry, 50(3): 435-438. 


\section{SALEH AL-BUSAFI, ET AL.}

BEGUM, S., SULTANA, R., SIDDIQUI, B.S., 1997. Triterpenoids from the leaves of Nerium oleander. Phytochemistry, 44(2): 329-332.

CUVELIER, M.E., BRAND-WILLIAMS, W. AND BERSET, C. 1995. Use of a free radical method to evaluate antioxidant activity. Lebensmittel-Wissenschaft und Technologie, 28: 25-30.

CUVELIER, M.E., RICHARD, H., BERSET, C., 1996. Antioxidative activity and phenolic composition of pilot-plant and commercial extracts of sage and rosmary. J. Am. Oil Chem. Soc., 73(5): 645-652.

DURET, S., PARIS, R.R., 1977. Distribution and metabolism of polyphenols in Nerium oleander. II . New studies on flavonoids and chlorogenic acid. Bull. Soc. Botan. France, 124(9): 503-524.

EL-HAMOULY, M., MOHAMED, T., 2001. Phytochemical and biological evaluation of volatile constituents of Zizyphus spina-christi. Al-Azhar J. Pharm. Sci., 28: 370-379.

EL- TAHIR, K.E., 1991. Pharmacological action of magnoflorine and aristolochic acid-1 isolated from the seeds of Aristolochia bracteata. Int. J. Pharmacogn, 29(2): 101-110.

GHAZANFAR, S.A., 1994. CRC Handbook of Arabian Medicinal Plantsm ( $1^{\text {st }}$ Edition) CRC Press, Inc., Boca Raton, FL. (USA) pp. 265

HATAM, N.A.R., WHITING, D.A., YOUSIF, N.J., 1989. Cucurbitacin glycosides from Citrullus colocynthis. Phytochemistry, 28(4): 1268-1271.

HISHAM, A., PATHARE, N., AL-SAIDI, S. and AL-SALMI, A., 2006.The Composition and antimicrobial activity of leaf essential oil of Teucrium mascatense (Boiss.) from Oman. Journal of Essential Oil Research 18: 465-468.

MAATOOQ, G.T., EL-SHARKAWY, S.H., AFIFI, M.S., ROSAZZA, J.P.N., $1997 . \quad$ C-Phydroxybenzoylglycoflavones from Citrullus colocynthis. Phytochemistry, 44(1): 187-190.

MADSEN, H.L., BERTELSEN, G., 1995. Spices as antioxidants. Trends Food Sci. Technol., 6: 271-277.

MANDAVILLE, J.P.Jr., 1978. Wild Flowers of Northern Oman ( $1^{\text {st }}$ Edition) John Bartholomew \& Son Ltd., pp. 29.

MANDAVILLE, J.P.Jr., 1978. Wild Flowers of Northern Oman ( $1^{\text {st }}$ Edition) John Bartholomew \& Son Ltd., pp. 40.

MILLER, A.G., MORRIS, M., 1988. Plants of Dhofar ( $1^{\text {st }}$ Edition) the Office of the Adviser for Conservation of the Environment, Diwan of Royal Court, Sultanate of Oman, pp.242-243.

MILLER, A.G., MORRIS, M., 1988. Plants of Dhofar ( $1^{\text {st }}$ Edition) the Office of the Adviser for Conservation of the Environment, Diwan of Royal Court, Sultanate of Oman, pp.176-177.

MILLER, A.G., MORRIS, M., 1988. Plants of Dhofar ( $1^{\text {st }}$ Edition) the Office of the Adviser for Conservation of the Environment, Diwan of Royal Court, Sultanate of Oman, pp.120-121.

MUHAISEN, H.M., ILYAS, M., MUSHFIQ, M., PARVEEN, M., BASUDAN, O.A., 2002. Flavonoids from Acacia tortilis. J. Chem. Res., 6: 276-278.

PRIETO,P.; PINEDA, M. and AQUILAR, M. 1999. Spectrophotometric quantitation of antioxidant capacity through the formation of a phosphomolybdenum complex: specific application to the determination of vitamin E. Anal. Biochem., 269:337-341.

RAMACHANDRAN, R., ALI, M., 2003. Isolation and characterization of acyclic terpenic constituents from Cressa cretica aerial parts. J. of Med. and Arom. Plants Sci., 25(1): 81-90.

SHAHAT, A.A., ABDEL-AZIM, N.S., PIETERS, L., VLIETINCK, A.J., 2004. Flavonoids from Cressa cretica. Pharm. Biol. (Lisse, Netherlands), 42(4-5): 349-352.

Received 27 January 2007

Accepted 31 October 2007 